\title{
Consumer use intention of online financial products: the Yuebao example
}

\author{
Huosong Xia* and Zhe Hou
}

\author{
* Correspondence: \\ 1179094639@qq.com \\ School of management, Wuhan \\ Textile University, Wuhan, China
}

\begin{abstract}
Drawing on a valence framework and innovation diffusion theory, this study examines Yuebao deployment to model consumers' intention to use financial products offered online. We collect data via an online survey among a young age bracket and use a VisualPLS graphic interface to test our model. The results indicate that first, compatibility and advantages in relative utility significantly enhance consumers' use intentions and that ease of use has an indirect influence. Second, the negative utility of perceived risk no longer significantly affects intention to use. This mainly lies in consumers' perceived risk focused on the security of online financial products, which has become a part of all online transactions. Third, trust indirectly affects intention to use by influencing utility.

Keywords: Online financial products, Utility, Trust, Innovation diffusion theory, Use intention, Yuebao
\end{abstract}

\section{Background}

In recent years, online financial products have become increasingly popular among Chinese consumers, thereby, arousing the interest of senior Chinese financial managers, the four main Chinese state-owned banks, and researchers in the field. An example of this trend is Yuebao. Alipay, a Chinese third-party payment platform, and Tianhong Asset Management jointly launched an innovative product involving payment and investment named Yuebao on June 13, 2013. By the end of June, Yuebao had 2.5 million users and the transaction scale had reached RMB 6.6 billion. In early September, its transaction scale was close to RMB five billion. Pushed by the explosive growth of Yuebao users, Tianhong Asset Management's fund was shown to be the largest public fund in China based on the most users. Yuebao's success stimulated more fund practitioners to participate in online finance and generated numerous online financial products similar to Yuebao. The emergence of these products has expanded the boundaries of financial services. Online finance has unveiled a new world for personal finance that has led to more fierce competition among traditional financial institutions.

The Data Report on Yuebao Running for the First Year, published by Tianhong Asset Management, showed that as of June 30, 2014, Yuebao had achieved the 100 million user milestone and in the second quarter, its earnings per capita was RMB 5030, thus indicating that most users held only a small amount of the fund (http://finance.ifeng.com/ a/20140702/12641772_0.shtml). Obviously, the numbers of people using online financial products has grown, reflecting a huge demand for financing in China; furthermore, many

(c) The Author(s). 2016 Open Access This article is distributed under the terms of the Creative Commons Attribution 4.0 International License (http://creativecommons.org/licenses/by/4.0/), which permits unrestricted use, distribution, and reproduction in any medium, provided you give appropriate credit to the original author(s) and the source, provide a link to the Creative Commons license, and indicate if changes were made. 
of these customers are not covered by traditional financial institutions and turn to online finance options. In contrast with the number of registered users on Alipay, namely, 8 billion (as of July 2013), the number of Yuebao users can still increase. However, the smaller average investment in online financial products indicates that consumers' level of acceptance of online financial products can be further improved.

Why do online financial products, such as Yuebao, achieve such rapid expansion? Which consumer behavior characteristics are responsible for this phenomenon? How do consumers choose products from among numerous similar products provided by different online financial product platforms? There are few studies on this topic. This study explores the theoretical value and application of online financial product platforms in practice. Through research on the use intention of online financial products such as Yuebao, this study provides ideas, references, and theoretical guidance for the development of future online financial services, along with ideas for creating innovative financial products from traditional financial institutions. The structure of the paper is as follows: first, relevant theory from a research perspective is discussed and a research model is proposed by analyzing and logically examining literature and associated phenomena; second, the data acquired from frequent users is presented along with conveniently accessible statistics to perform model verification; and finally, the discussion and conclusion are presented.

\section{Theoretical basis}

The 2013 Investigation Report on Chinese E-banks pointed out that in a narrow sense, online finance is a method that achieves financing through the Internet; in a broad sense, any application that uses the essence of the Internet and generalized finance can be regarded as online finance. Online finance models mainly include financial third party payments, P2P (peer-to-peer) network loans, e-commerce big data finance, crowdfunding, online financial institutions, online financial portal/financial e-commerce, innovative online financial products (such as Yuebao), and financial value-added services. In terms of online finance, research on consumers' behavioral intention has focused on e-commerce, e-banking, Internet security, and mobile payments. These studies generally apply the technology acceptance model (TAM) and the theory of planned behavior (TPB). Although more general studies on online financial products are also found in the available literature, few studies have been conducted from the consumer's perspective.

The TAM was proposed by Davis (1986) and Davis et al. (1989) on the basis of the TPB and the theory of rational behavior to explain users' acceptance behaviors toward a new technology. Owing to the simplicity of the model and the verification of its value in various empirical studies, the TAM has become widely used in studies on the acceptance of a wide array of information technologies. However, Kim (2007) pointed out that some traditional technology acceptance models are insufficient to explain users' acceptance behaviors toward new information and communication technology (ICT) (e.g., mobile payment technology) because consumers utilizing new ICT are automatically users of both the technology and the service. Thus, Yang et al. (2012a) indicated that the validity of some studies has been gradually questioned. In this context, online mobile users are not only adopters of new technology or information systems but also consumers of the mobile value-added service, and, in this case, value maximization is the most basic principle for decision making. 
Online financial products, such as Yuebao, are innovative products that offer both payment and investment options. Therefore, Yuebao users are not only users of online (mobile) payment technology but also investors who make decisions based on earnings and the comparison of potential risks. From the investment perspective, obviously, risk and earnings are positively related. In the online context, this means that only when consumers are ensured of a positive investment (after comparing earnings and risk) will they be willing to participate in online financial products.

In their seminal work, Peter and Tarpey (1975) presented a valence framework, assuming that consumers could detect positive and negative properties of products and then make decisions by maximizing net price valence (difference between positive and negative utility). Consumers' perceived risk and perceived profit are the two most fundamental aspects shaping consumer decisions in the valence framework, including perceived negative and positive utility; therefore, the users' decision-making process can be expressed as F (perceived earnings and perceived risk). Kim et al. (2008; 2009a) applied the valence framework to e-commerce scenarios and was able to provide better explanations for consumers' online shopping behaviors.

Thus, exploration of the use intention of online financial products from the perspective of utility is more consistent with the adoption behavior of financial products in the online financial scenario. Internet financial products are essentially still just financial products. The valence framework provides a foundation for research on consumers' decision making from the perspective of utility. At the same time, online financial products can also be seen as financial innovations. The innovation diffusion theory (IDT) reveals the fundamental differences and advantages between online financial products and traditional financial products.

\section{Research model and hypothesis}

Positive utility: innovation diffusion theory

Compared with traditional monetary funds, the innovations in online financial products manifest in the marketing channel and specific digital product features. Therefore, we shall consider the positive effect of these innovations. The IDT believes that innovation diffusion is a process in which a product, a service, or an idea penetrates and is widely adopted by a social system through different channels. IDT defines a series of innovation factors that influence user acceptance behaviors, including relative advantage, compatibility, individual image, complexity, trialability, foreseeability, and result presentation. After conducting an element analysis of 75 studies on innovative characteristics influencing the adoption of innovation, Tornatzky and Klein (1982) noted that compatibility, relative advantage, and complexity most significantly influence the adoption of innovation. From the perspective of channel selection for consumers, Choudhury and Karahanna (2008) studied the influence of the relative advantages of e-channels on consumers' use intention. Based on the valence framework, Yang et al. (2012b) studied the initial intention of adopting mobile payment from the perspective of technical attributes using relative advantage and compatibility as positive utilities. Their study verified that relative advantage and compatibility have a significantly positive impact on consumers' willingness to use mobile payment options and the explanatory ability of the valence framework. 
Relative advantage refers to the degree the user perceives there is an advantage in the adoption of a certain innovative technology compared with existing technology. Thus, this study defines the relative advantages of online financial products compared with traditional financing as including the following: being convenient and enabling a quick purchase, having a low threshold requirement, providing a high return, and having strong liquidity. Compatibility refers to the degree of accordance (Rogers 1995) between an innovation and any potential user's existing value, experience, and current demand for its use. The more insistent the user's current demands, the more likely the product will be utilized and disseminated. Therefore, in this study, compatibility is defined as the degree of accordance between the consumer's consideration of using online financial products and his/her value, experience, and demand for its use. Based on the above analysis, the following hypotheses are proposed:

Hypothesis 1: The relative advantages of online financial products positively influence use intention

Hypothesis 2: The compatibility of online financial products positively influences use intention

Moore and Benbasat (1991) noted in their research that "complexity" in IDT is similar to "ease of use" in the TAM. Due to the negative impact of complexity on use intention, this study adopts the ease of use concept in the discussion of the positive utility of online financial products. Ease of use reflects users' operational experience with respect to online financial products; thus, it refers to users' experienced level of ease in understanding or operating such innovations. The stronger the ease of use, the higher the users' adoption degree toward a new product, and therefore, the more likely they are to use the product willingly. Thus, the following hypothesis is proposed:

Hypothesis 3: Ease of use of online financial products positively influences use intention

Consumers who are familiar with and accustomed to online and mobile payments are more likely to acknowledge online marketing channels. In addition to their demands for personal finance, these consumers are likely to have increased perceptions of the relative advantages of online financial products. Based on this, the following hypotheses are proposed:

Hypothesis 4: Ease of use of online financial products positively influences relative advantage.

Hypothesis 5: The compatibility of online financial products positively influences relative advantage.

\section{Negative utility: perceived risk}

In terms of users' perceived negative utility, the original valence framework measures perceived risk. Ostlund (1974) proved that perceived risk affects consumer adoption behavior toward innovative products and that a significant negative correlation exists between them. The 2013 Investigation Report on Chinese E-banks indicated that one of 
the disadvantages of Yuebao was that users doubted the security of Alipay. Considering the smaller risk of financial loss in purchasing online financial products (e.g., money market funds), the perceived risks mainly involved the unpredictability of account security. In a study on the use intention of mobile wallets, Shin (2009) proved that perceived security significantly affected consumers' intention to use mobile wallets. Peng et al. (2013) indicated in their study on adoption intention of mobile payments that perceived risk restricted mobile payment adoption. Therefore, in this study, perceived risk is defined as the security risk perceived by consumers when using online channels. Hence, the following hypothesis is proposed:

Hypothesis 6: Perceived risk has a significant negative impact on use intention of online financial products.

\section{Trust}

Trust plays a crucial role in exchanges involving unknown risks. Relevant literature reveals that trust has a significant impact on users' willingness to engage in online transactions related to money and sensitive personal information (Friedman et al. 2000). Furthermore, users' trust in a product or service accumulated over a long period of time will influence their perceived trust in another product or service from the same channel (Lee et al. 2007). Only those users who trust Alipay after transactions on Taobao or Alipay will try Yuebao as one of Alipay's clients. Yuebao is essentially a money fund under Tianhong Asset Management. However, this Tianhong Money Fund was originally unknown. It is only through its involvement in the Alipay system that it has become known to the users of Taobao and Alipay who access such financial products. Thus, irrespective of the fund Alipay has cooperated with, Alipay users have been willing to try it. We can, therefore, assume that consumers' trust in Alipay is one of the factors influencing them to try Yuebao. The trust defined in this study refers to consumers' trust in an online financial products platform. Thus, the following hypothesis is proposed:

Hypothesis 7:Trust has the following hypothesises 7a through 7d.

Hypothesis 7a: Trust has a significantly positive impact on use intention of online financial products.

From the perspective of risk and trust, Chen et al. (2014) studied the lending intention of PPDai, which was mainly influenced by trust. In research on use behavior of virtual currency, Zhao and Wang (2013) indicated that trust acted on behavioral intention by affecting technical usefulness and ease of use. Based on the uncertainty of the e-commerce environment, Pavlou (2003), in his research on the adoption behavior of e-commerce, discovered that consumers' trust in any supplier not only affected their use intention directly but also indirectly affected it by lowering their perceptions of risk. He also labeled trust as an important antecedent of perceived usefulness and ease of use. Kim et al. (2009b) proved that trust could indirectly influence consumer intention to use e-commerce by reducing perceived risks and increasing perceived earnings. In other words, trust can lower users' negative utility perceptions and increase their positive utility perceptions. Thus, the following hypotheses are proposed: 
Hypothesis 7b: Trust has a significantly negative impact on perceived risk of online financial products

Hypothesis 7c: Trust has a significantly positive impact on the ease of use of online financial products

Hypothesis 7d: Trust has a significantly positive impact on the relative advantages of online financial products

Hypothesis 7e: Trust has a significantly positive impact on the compatibility of online financial products

Based on the valence framework, this study combines trust with the theories of relative advantage, compatibility, and perceived risk to construct a theoretical research model. The research model and hypotheses are illustrated in Fig. 1.

\section{Research method}

\section{Variable design and measurement}

A questionnaire was developed in two stages. In the first stage, a literature review was conducted related to original questions about the variables. Some questions were then taken from the literature and modified to adapt them here for the online financial product scenario. The original measurement questions regarding relative advantage were effectively verified in numerous information technology systems. To enhance the applicability of the model for the online financial product scenario, new questions regarding relative advantage were developed through our team's brainstorming, especially with respect to collective input. In the second stage, a small, pre-survey was conducted. According to the 90 questionnaires collected through the pre-survey, some measurement items were partially modified to create the final questionnaire. The research model contains five variables that adopt multiple indices for measurement. A seven-point

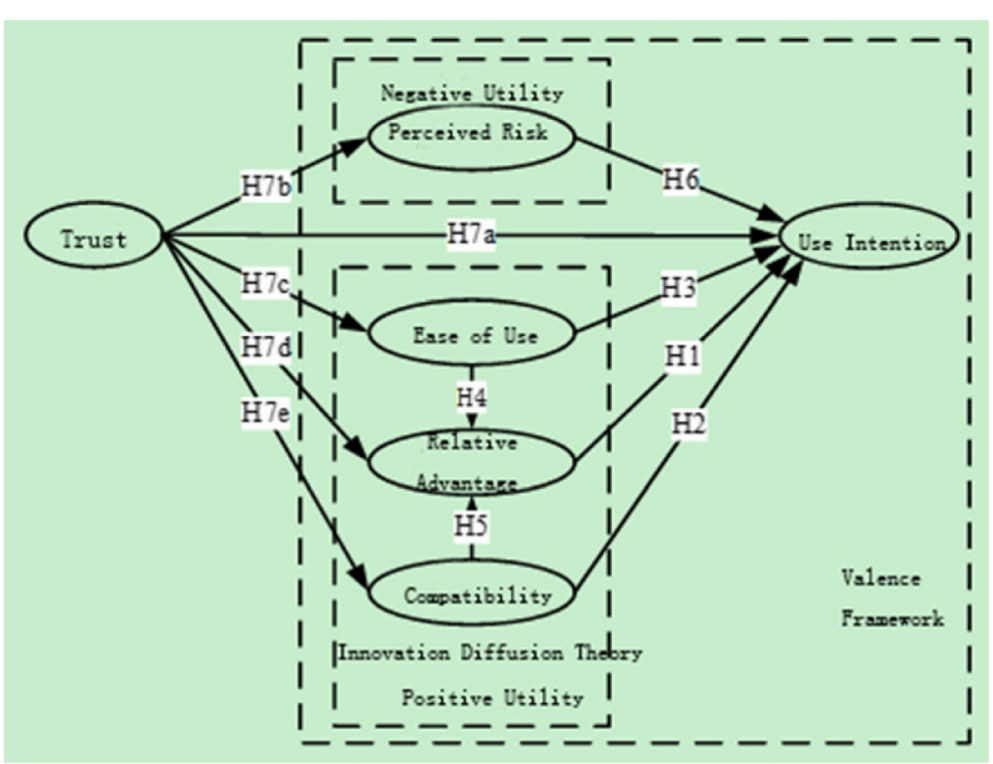

Fig. 1 Research model 
Likert scale was applied to measure the responses, where "1" represents "strongly disagree" and "7" represents "strongly agree," as shown in Table 1.

\section{Data collection and sample characteristics}

The target respondents in this study are users experienced in online financial products. The 2013 Investigation Report on Chinese E-banks indicated that the general age bracket of consumers using online financial products is $20-29$ years. The target respondents here were concentrated in the age bracket of 18-40 years. The research was conducted through snowball sampling. First, relatives and friends of the target personnel were invited to fill in the questionnaire and were asked to forward the questionnaire to their Wechat Moments, from where they could invite their friends and relatives to further pass on the questionnaire. Thus, using this snowballing approach, the sample size continuously expanded, as compared with other sampling techniques. We believe this approach obtains a highly credible response (Biernacki \& Waldorf 1981). A total of 202 questionnaires were collected. The respondents included 117 men (57.92\%) and 85 women (42.08\%); 94.06\% of the respondents

Table 1 Measurement item and source of variables

\begin{tabular}{|c|c|c|c|}
\hline Variable & $\begin{array}{l}\text { Measurement } \\
\text { item }\end{array}$ & Question item & Source \\
\hline \multirow[t]{3}{*}{ Use Intention, UI } & UI1 & I have used or will start using Yuebao soon. & \multirow{3}{*}{$\begin{array}{l}\text { (Davis 1986; } \\
\text { Gefen et al. 2003) }\end{array}$} \\
\hline & UI2 & I intend to continue using Yuebao in the future. & \\
\hline & UI3 & $\begin{array}{l}\text { I am willing to provide my bank card information } \\
\text { to Yuebao. }\end{array}$ & \\
\hline \multirow[t]{3}{*}{ Ease of use, EU } & EU1 & It is easy to learn how to use Yuebao. & \multirow[t]{6}{*}{ (Pavlou 2003) } \\
\hline & EU2 & It takes less effort to master the operation of Yuebao. & \\
\hline & EU3 & $\begin{array}{l}\text { It is easy to understand the operation steps and } \\
\text { procedure of Yuebao. }\end{array}$ & \\
\hline \multirow[t]{3}{*}{$\begin{array}{l}\text { Relative } \\
\text { Advantage, RA }\end{array}$} & RA1 & $\begin{array}{l}\text { Compared to traditional financial products, Yuebao } \\
\text { has low investment thresholds and thus improves } \\
\text { the utilization rate of idle funds. }\end{array}$ & \\
\hline & RA2 & $\begin{array}{l}\text { Compared to traditional financial products, Yuebao } \\
\text { has a higher return rate, faster liquidity, and lower risk. }\end{array}$ & \\
\hline & RA3 & $\begin{array}{l}\text { Compared to traditional financial products, Yuebao } \\
\text { is more convenient and faster. }\end{array}$ & \\
\hline \multirow[t]{3}{*}{ Compatibility, CO } & $\mathrm{CO} 1$ & $\begin{array}{l}\text { The use of Yuebao meets my financial management } \\
\text { demand. }\end{array}$ & \multirow[t]{3}{*}{ (Rogers 1995) } \\
\hline & $\mathrm{CO} 2$ & The use of Yuebao is suitable to my lifestyle. & \\
\hline & $\mathrm{CO} 3$ & $\begin{array}{l}\text { The use of Yuebao is suitable to my product and service } \\
\text { purchasing habit (e.g., online shopping). }\end{array}$ & \\
\hline \multirow[t]{3}{*}{ Perceived Risk, PR } & PR1 & $\begin{array}{l}\text { I am concerned that my personal information and } \\
\text { bank card information will be leaked or stolen when } \\
\text { I use Yuebao. }\end{array}$ & \multirow[t]{3}{*}{$\begin{array}{l}\text { (Featherman \& } \\
\text { Pavlou 2003) }\end{array}$} \\
\hline & PR2 & $\begin{array}{l}\text { I am concerned that the Yuebao payment system is } \\
\text { insecure. }\end{array}$ & \\
\hline & PR3 & I think it is risky to put money in Yuebao. & \\
\hline \multirow[t]{3}{*}{ Trust, TR } & TR1 & Alipay is reliable. & \multirow[t]{3}{*}{ (Pavlou 2003) } \\
\hline & TR2 & Alipay is credible. & \\
\hline & TR3 & Alipay cares about users' benefits. & \\
\hline
\end{tabular}


were in the $18-30$ year age bracket; $63.86 \%$ of the respondents frequently used mobile payment (more than once a week). In terms of the preferred investment amount in Yuebao, the largest number, 36.14\%, of the respondents were only willing to invest less than RMB 5000, 27.72\% were willing to invest between RMB 5000-10,000, 25.25\% between RMB 10,000-50,000, and 10.89\% RMB 50,000 or above.

\section{Data analysis and hypothesis testing}

Data analysis and hypothesis testing were conducted through SPSS and partial least squares (PLS). PLS can test both the measurement and structure models, process small data samples, and does not require a normal distribution of samples. Hence, PLS was adopted for hypothesis verification and path analysis in this study.

\section{Measurement model analysis}

This study adopted principle components and factor analysis and confirmatory factor analysis for measurement model testing.

\section{(1)Principle Components and Factor Analysis}

First, varimax rotation was used for principle components analysis. The Kaiser-MeyerOlkin (KMO) statistic of the sample data was 0.891. As it was located between 0.8 and 0.9 , it indicated that the sample was suitable for factor analysis. Six factors extracted from the factor-loading matrix after varimax rotation completely explained $84.481 \%$ of the variance, while the loading of all indices on their corresponding factors was much more than the cross loading on other factors. The statistics indicated that all indices were capable of effectively reflecting their corresponding factors, thus ensuring better measurement validity.

(2) Confirmatory Factor Analysis

This study adopts confirmatory factor analysis (CFA) to examine variable reliability, convergent validity, and discriminate validity. Reliability was measured by average variance extracted (AVE), composite reliability (CR), and Cronbach's $\alpha$. Among the three indices, Cronbach's $\alpha$ was applied to measure the degree of the variables' internal consistency. When Cronbach's $\alpha$ is greater than 0.7 , the reliability of the theoretical model is generally validated (Burkink 2002). Convergent validity reflects the theoretical and practical correlation degree between measurement indices, and CR and AVE can be used for its measurement. When CR $>0.7$ and AVE $>0.5$, good convergent validity of a certain variable is indicated. Through CFA, the Cronbach $\alpha$ for all variables was above 0.7, while their AVE values were above 0.5 and their $C R$ values above 0.9 . Thus, the data were found to have good stability and consistency, while the measurement model had good reliability and convergent validity.

Discriminate validity indicates that the measurement reflects the variable itself rather than other variables. In comparison, the square root of AVE was much greater than the absolute value of the correlation coefficient between latent variables, thus indicating good discriminate validity of such variables. 


\section{Structure model analysis}

This study adopted Visual PLS 1.04 to analyze the structure model and utilized bootstrap to estimate each route system's significance level. The analysis of the structure model is illustrated in Table 2. The path for all hypotheses and significance levels are shown in the Table.

The path coefficient between ease of use and use intention was unremarkable, indicating that consumers' perception of ease of use for online financial products was not an essential factor hindering their online transactions as was the case at the beginning of the Internet age. Consumers' online payment and purchasing behaviors (especially among the young) have matured. The utility engendered by unit risk was mainly considered as the main factor affecting consumers' decision-making behaviors. However, the influence of ease of use on use intention was manifest by indirectly affecting relative advantage.

Perceived risk was unremarkable to the path coefficient of use intention. This discovery was consistent with the research conclusion drawn by Zhou et al. (2009). However, the average value of consumers' perceived risk was 5.06, indicating that consumers were still willing to make online payments and try online financial products even if the perceived risk existed. In tandem with the rapid development of online transaction and payment systems and the increased popularity of online payments, our respondents also indicated a higher frequency of use of online payments. In addition, most respondents were young people aged 20-30 years who are more prone to be impulsive and willing to try new financial management options of online financial products. Finally, the security risk of online financial products was mainly reflected in payment, account, and privacy security. Perceived risk is less important today for consumers already accustomed to the use of online and mobile payment methods and who have deemed online payments as an essential part of their lives.

The path coefficient between trust and use intention was unremarkable. The effect of trust on use intention was achieved by indirectly influencing relative advantage, perceived risk, and ease of use. Trust can reduce consumers' perceptions of risk, which is an important antecedent of the positive utility of online financial products.

Table 2 Model verification result

\begin{tabular}{|c|c|c|c|c|}
\hline Hypothesis & Route & Route coefficient & t-value & Conclusion \\
\hline $\mathrm{H1}$ & Relative Advantage $\rightarrow$ Use Intention & 0.329 & $3.390(* * *)$ & Supported \\
\hline $\mathrm{H} 2$ & $\begin{array}{l}\text { Compatibility } \rightarrow \\
\text { Use Intention }\end{array}$ & 0.301 & $4.725(* * *)$ & Supported \\
\hline $\mathrm{H} 3$ & $\begin{array}{l}\text { Ease of use } \rightarrow \\
\text { Use Intention }\end{array}$ & 0.114 & 1.512 & Not Supported \\
\hline $\mathrm{H} 4$ & Ease of use $\rightarrow$ Relative Advantage & 0.378 & $4.395\left(*^{* *}\right)$ & Supported \\
\hline H5 & Compatibility $\rightarrow$ Relative Advantage & 0.300 & $3.607(* * *)$ & Supported \\
\hline H6 & $\begin{array}{l}\text { Perceived Risk } \rightarrow \\
\text { Use Intention }\end{array}$ & -0.091 & -1.900 & Not Supported \\
\hline $\mathrm{H7a}$ & Trust $\rightarrow$ Use Intention & 0.160 & 1.797 & Not Supported \\
\hline $\mathrm{H} 7 \mathrm{~b}$ & Trust $\rightarrow$ Perceived Risk & -0.370 & $-5.879\left(^{* * *}\right)$ & Supported \\
\hline $\mathrm{H} 7 \mathrm{C}$ & Trust $\rightarrow$ Ease of use & 0.551 & $11.302\left({ }^{* * *}\right)$ & Supported \\
\hline $\mathrm{H} 7 \mathrm{~d}$ & $\begin{array}{l}\text { Trust } \rightarrow \\
\text { Relative Advantage }\end{array}$ & 0.150 & $1.973\left(^{*}\right)$ & Supported \\
\hline $\mathrm{H} 7 \mathrm{e}$ & Trust $\rightarrow$ Compatibility & 0.540 & $10.205\left({ }^{* * *}\right)$ & Supported \\
\hline
\end{tabular}

Note: $|\mathrm{t}|<1.96$ represents invalid hypothesis; $1.96<|\mathrm{t}|<2.58$ represents significance level ${ }^{*} p<0.05 ; 2.58<|\mathrm{t}|<3.29$ represents significance level ${ }^{* *} p<0.01 ; 3.29<|t|$ represents significance level ${ }^{* *} p<0.001$ 
By affecting the positive utility of online financial products, it indirectly affected consumers' use intention.

In general, the five variables, relative advantage, compatibility, ease of use, trust, and perceived risk, reached $61.9 \%$ of explanatory ability for use intention, thus indicating strong explanatory functions.

\section{Discussion and conclusion}

Through research on related phenomena in popular online financial products in China, this study revealed a "model of consumers' use intention toward online financial products." The theoretical contribution of this study is as follows: considering Yuebao as an example of data for model verification, the study theoretically explained consumer behavior of accepting online financial products from the perspectives of utility and innovation; combined with the features of Chinese online financial products, it built a scale of relative advantage; on the basis of existing literature and theories, it expands the application scenario of the IDT. Empirical results suggest that relative advantage and compatibility of online financial products are the fundamental factors influencing consumer behavior intention. Although trust had no direct effect on behavior intention, it was an important antecedent that affected consumer behavior intention.

The practical value of this study is mainly embodied in the following four aspects and associated recommendations:

1) The remarkable influence of compatibility on consumers' use intention reflects the "internetization" of consumer behavior. With the popularity of the Internet and the mobile Internet, consumer behaviors and habits have changed significantly. The contact method for financial products has also changed, and online financial management is increasingly becoming the favored approach. Traditional financial institutions need to improve their construction of digital channels and emphasize the integration advantage and complementary nature between traditional financial business and online financial business to remain in sync with online financial development trends.

2) Relative advantage embodies the core advantage and competitiveness of online financial products. The investment threshold requirement to buy a bank's short-term financial product is generally RMB 50,000; medium and small investors still consider this a high threshold. However, the investment threshold for a financial product such as Yuebao is only RMB 1 yuan, which caters to "grassroots" or "pleb" investors and encourages them to participate; in terms of the rate of return, Yuebao has been capable of offering higher earnings and supporting multiple functions such as online shopping, payment, and transfer since it was first launched during a money shortage period in 2013. It combines other life functions with financial management. It is also easy to operate through a computer or mobile phone anywhere at any time. Users can conveniently enjoy financial services and check earnings every day. People who are unable to obtain services from traditional financial systems or are too "lazy" to manage their finances due to geographic or time inconveniences are willing to use online financial services. These advantages are the fundamental reasons behind the popularity of Yuebao, thus highlighting that product and service innovation should be implemented for and focused on consumer needs. Commercial banks need to 
transform from a "bank focus" to a "customer focus," cultivating "online thinking," exploring customer needs, and focusing on customer experience. As an example, to establish its core competitiveness, Yuebao is providing distinct and comprehensive financial services based on detailed client demands.

3) In terms of perceived risk, online financing platforms should improve Internet security and focus on the protection of consumers' privacy and fund security as well as emphasize the risk management of financial products. Traditional monetary market funds adopt the $\mathrm{T}+1$ subscription and redemption system, which is a fundamental risk buffer and management system. Yuebao adopts the $\mathrm{T}+0$ subscription and redemption system. $\mathrm{T}+0$ considers Alipay's advance funds as its foundation. It improves fund liquidity and the consumers' user experience; however, there is no buffer time once the risk of a bank run arises. Compared to Yuebao's scale, Alipay's advance funds are just a drop in the bucket (Wang 2014). In targeting consumers, it is necessary to improve their knowledge of financial management and risk awareness so they can weigh various elements such as rate of return, risk, liquidity, and purchase platform to select suitable online financial products.

4) In terms of supervision, there is a vacuum in online financial supervision today. The construction and enforcement of laws and regulations is needed for the regulating authority to guide and standardize financial innovations such as Yuebao; at the same time, the construction of consumer protection mechanisms should be continuously strengthened to promote their effective implementation. Through industry self-regulation and supervision, a sound online financial environment can be constructed to boost consumer confidence in the investment environment and platform as well as promote the healthy and sustainable development of online finance.

This study has the following limitations. Some of the hypotheses were not supported by empirical evidence; for example, perceived risks are utilized to simplify the models. The study can be further improved with a better theory for revelation. Moreover, the data collected for verification in the study targeted young consumers, therefore consumers' perceived risk mainly concerned security risk; however, risks related to the financial products themselves, for example, policy risk, liquidity risk, and financial risk, were not examined. We thus recommend further exploration of the abovementioned concerns.

\section{Acknowledgements}

We deeply appreciate the language editor from Xingtong Chen. We also deeply appreciate the suggestions from fellow members of Xia's project team and Research center of Enterprise Decision Support, Key Research Institute of Humanities and Social Sciences in Universities of Hu Bei Province. 


\section{Authors' information}

Dr. Huosong Xia is a professor in the school of management of the Wuhan Textile University. He was a visiting scholar at Eller College of Management of the University of Arizona, USAfrom 2006 to 2007. His main research interests are: knowledge management,data mining and,e-Commerce and Logistics Information System. His publications have appeared in refereed international journals such as Journal of Knowledge Management, International Journal of Knowledge Management, Journal of Knowledge Management Practice Journal of Systems Science and Information, Journal of Grey System. He may be contacted at E-mail Box: 1179094639@qq.com;bxxhs@sina.com

\section{Competing interests}

The authors declare that they have no competing interests.

Received: 26 October 2016 Accepted: 28 November 2016

\section{Published online: 02 December 2016}

\section{References}

Biernacki P, Waldorf D (1981) Snowball Sampling: Problems and Techniques of Chain Referral Sampling [J]. Sociol Methods Res 10(2):141-163

Burkink T (2002) Cooperative and voluntary wholesale groups:channel coordination and inter firm knowledge transfer [J]. Supply Chain Manag 7(2):60-70

Chen D, Zhu H, Zheng H (2014) Risk, Trust and Lending Intention - Empirical Research on PPDAl Registered Users [J]. Manag Rev (1)

Choudhury V, Karahanna E (2008) The relative advantage of electronic channels: a multidimensional view [J]. MIS Q $: 179-200$

Davis F D (1986) Perceived usefulness, perceived Ease of use, and user acceptance of information technology [J]. MIS Q:319-340.

Davis FD, Bagozzi RP, Warshaw PR (1989) User acceptance of computer technology: a comparison of two theoretical models [J]. Manag Sci 35(8):982-1003

Featherman MS, Pavlou PA (2003) Predicting e-services adoption: a perceived risk facets perspective [J]. Int J Hum Comput Stud 59(4):451-474

Friedman B, Kahn P, Howe D (2000) Trust online. Commun ACM 43:34-40

Gefen D, Karahanna E, Straub DW (2003) Trust and TAM in online shopping: an integrated model [J]. MIS Q 27(1):51-90

Kim HW, Chan HC, Gupta S (2007) Value-based adoption of mobile internet: an empirical investigation [J]. Decis Support Syst 43(1):111-126

Kim DJ, Ferrin DL, Rao HR (2008) A trust-based consumer decision-making model in electronic commerce: The role of trust, perceived risk, and their antecedents [J]. Decis Support Syst 44(2):544-564

Kim DJ, Ferrin DL, Rao HR (2009) Trust and satisfaction, two stepping stones for successful e-commerce relationships: a longitudinal exploration[J]. Inf Syst Res 20(2):237-257

Lee KC, Kang I, McKnight DH (2007) Transfer from offline trust to key online perceptions: An empirical study [J]. IEEE Trans Eng Manag 54(4):729-741

Moore GC, Benbasat I (1991) Development of an instrument to measure the perceptions of adopting an information technology innovation [J]. Inf Syst Res 2(3):192-222

Ostlund LE (1974) Perceived innovation attributes as predictors of innovativeness [J]. J Consum Res: 23-29

Pavlou PA (2003) Consumer acceptance of electronic commerce: integrating trust and risk with the technology acceptance model [J]. Int J Electron Commer 7(3):101-134

Peng H, Xu X, Liu W (2013) Study on Impetus and Resistance of Mobile Payment Adopters [J]. Manag Rev 25(12).

Peter JP, Tarpey LX Sr (1975) A comparative analysis of three consumer decision strategies [J]. J Consum Res: 29-37

Rogers E (1995) Diffusion of innovation. Free Press, New York

Shin DH (2009) Towards an understanding of the consumer acceptance of mobile wallet [J]. Comput Hum Behav 25(6): 1343-1354

Tornatzky LG, Klein KJ (1982) Innovation characteristics and innovation adoption-implementation: A meta-analysis of findings [J]. IEEE Trans Eng Manag 29(1):28-45

Wang F (2014) Thinking About Innovation of Internet Financial Products [J]. Int Financ 2:64-68

Yang Y, Zhang J, Man Q et al (2012a) Study on Adoption of Mobile Internet Users - From The Perspective of Benefit, Cost and Risk [J]. J Intelligence 1:200-206

Yang S, Lu Y, Cao Y (2012b) Initial Adoption Model of Mobile Payment Service and Its Empirical Research [J]. Chin J Manag 9:1365-1372

Zhao Q, Wang X (2013) Empirical Research on Virtual Currency Payment Behavior of TAM/TPB Integration Model [J]. Forecasting 32(3):55-59

Zhao T, Lu Y, Zhang J (2009) Study on Acceptance Behavior of Mobile Commerce Based On Perceived Value and Trust [J]. Chin J Manag 10:1407-1412 